\title{
Three-dimensional random Voronoi models for simulation of brittle rock damage around underground excavations in laminated ground
}

\author{
E Ghazvinian Mine Design Engineering, Canada \\ KS Kalenchuk Mine Design Engineering, Canada \\ MS Diederichs Queen's University, Canada
}

\begin{abstract}
Three-dimensional Voronoi tessellations are utilised to demonstrate the simulation of brittle damage around underground mine excavations. Synthetic rock mass models are developed based on calibrated simulations that have been up-scaled to represent excavation-scale rock mass conditions. Rock mass anisotropy plays a significant role in the stability of underground excavations, and so anisotropic conditions are replicated by implementing the up-scaled laminated grain-based model composed of elongated three-dimensional Voronoi blocks. Models explore the influence of the orientation of anisotropic fabric with respect to the in situ stress tensor to demonstrate the Voronoi-based discrete element method modelling technique for simulation of brittle failure. The numerical results verified the success of this approach in capturing the correct failure mode controlled by fabric-guided fracturing in the walls of deep undergrounds openings.
\end{abstract}

Keywords: numerical modelling, 3D Voronoi tessellation, excavation stability

\section{Introduction}

The simulation of fracturing and crack damage progression for brittle rocks can be performed implicitly in continuum or explicitly with the aid of discontinuum numerical approaches. In implicit simulation of micro-crack formation, the weakness caused by the formation of cracks is smeared within the material by means of constitutive relationships. The damage initiation-spalling limit approach is an example of implicit brittle fracture simulation with continuum codes (Diederichs 2007). The explicit simulation of micro-fracturing in rock-like material can be accomplished by direct representation of cracks in models formulated based on the discrete element method (DEM), (Cundall \& Hart 1985; Cundall 1988) or by using the hybrid finite-discrete element method (FDEM) codes (Mahabadi et al. 2012a). The work documented by Karampinos et al. (2015) and Garza-Cruz et al. (2014) are some examples of simulating fracturing in large-scale models within the DEM formulation.

In DEM, the rock-like material can be simulated as a dense assembly of rigid or deformable particles that interact at their contact points. Also, the discrete bodies can detach and new contacts can automatically be detected (Itasca 2013) and, therefore, fractures can be simulated at the grain (or block) boundary opening. In the bonded-particle model (BPM), which falls within the DEM formulation, the particles are represented by rigid disks in two-dimensional (2D) and rigid spheres in 3D (Potyondy \& Cundall 2004). The breakage of bonds between the spheres in the BPM is comparable to fracturing in rock. The BPM that is implemented in particle flow code (PFC), (Itasca 2008a, 2008b) has been used widely for crack damage simulation in rock. The concerns and possible solutions for the accuracy of PFC simulations have been documented in the past by many researchers, including Diederichs (2003), Potyondy and Cundall (2004), Cho et al. (2007), Yoon et al. (2008), Ghazvinian (2010), and Turichshev and Hadjigeorgiou (2016).

The random polygonal blocks (grains) in DEM are an alternative geometry to the disks and spheres employed in BPM approach for simulation of fracturing. Voronoi tessellation is one of the available 
techniques for generating the random polygonal grains within a domain. In this technique, a region is populated with random seed points. Lines or planar surfaces are generated so that the bounded region surrounding each seed point includes all the space that is closer to that seed point than any other. The grain boundaries in the poly-crystal structure produced by Voronoi tessellation can be used to represent flaws in intact rock and, therefore, allow for simulation of crack damage development through initiation and propagation of fractures along grain boundaries.

In the Voronoi modelling approach, for simulation of fracturing in intact rock, the grains (blocks) can be rigid, elastic or inelastic. The behaviour of contacts between the grains are commonly governed by the available constitutive formulations for rock mass joints and discontinuities. Some of the concerns associated with the formulation of bonded particle models (i.e. PFC) were demonstrated to be no longer applicable to the Voronoi method (Kazerani \& Zhao 2010; Lan et al. 2010). This lead to increasing the application of Voronoi grain-based models for simulation of fracture formation in rocks despite its poor computational speed compared to the BPM. While clumping and clustering in the BPM (Cho et al. 2007; Ghazvinian 2010) and the modifications to the BPM formulation (development of the flat-joint contact model (Potyondy 2012)) in recent years have solved the concerns with the accuracy of the BPM results to a great extent, the Voronoi-based grain-based models (GBMs) are still popular due to the simplicity of generating these models.

The presence of fabric in intact brittle rocks and the consequent anisotropic mechanical behaviour further adds to complexity of simulating brittle failure for those rocks. The state of practice approaches include equivalent continuum such as the ubiquitous joint model in FLAC (Itasca 2012), or the DEM or hybrid FDEM discontinuum approaches that either apply implicit anisotropic contact and material constitutive behaviour or introduce an anisotropic defect or pre-damage to the model (e.g. Diederichs et al. 2004; You et al. 2011; Kazerani 2013; Lisjak et al. 2014a). It is important to mention that, as far as modelling in isotropic or anisotropic brittle rock masses for common practice design work is concerned, continuum models provide a faster and easier solution (e.g. Sweby et al. 2016; Sharrock \& Cuello 2016; Vakili et al. 2014). However, when the simplifying assumptions in the continuum models cannot be tolerated, the rock mass mechanical response need to be coupled with hydro-thermal responses or when the continuum model responses need to be validated discontinuum modelling is required.

This paper demonstrates the application of 3D Voronoi tessellated model, introduced by Ghazvinian et al. (2014) for 3DEC, for fabric-guided fracturing surrounding deep underground excavations. By using this analogue for massive rock masses with inherent anisotropy, it is shown that the strength anisotropy of the rock mass can be solely captured by the geometrical factor of the Voronoi blocks (length to width ratio) with only one set of calibrated model properties used for different fabric orientations.

\section{$2 \quad$ Numerical approach}

\subsection{Voronoi tessellation method}

The extensile 'crack opening forces' at the micro-scale can be generated through different mechanisms. These mechanisms amplify the localised shear strains and subsequently facilitate the nucleation of inter-granular and intra-granular cracks at the crack initiation (Cl) threshold (Diederichs 2003). To simulate the extensile crack opening forces at the micro-scale in DEM models, the rigid or deformable particles are approximated by simple geometries. The three commonly used geometries are disks (spheres in 3D), (Potyondy \& Cundall 2004; Scholtès \& Donzé 2013), Voronoi grains (Damjanac et al. 2007), and triangles (tetrahedra in 3D), (Gao \& Stead 2014). The geometry of the particles plays a key role in the generation of the crack extension and shearing forces acting on the sliding fractures. The applied compressive forces in the Voronoi model can be resolved into extensile and shearing forces acting on the grain boundaries (sliding flaw in this case). In the circular disk model, the applied forces will translate into tensile stresses at the contact between the disks and rotational moments acting upon the disks. The geometrically-imposed restriction on the generation of shear stresses at the contacts between the disks in the BPM has a minor 
effect on the $\mathrm{Cl}$ threshold since most of the micro-cracks in brittle rocks form in tension (Diederichs 2007). However, with increasing deviatoric stress and on reaching the critical damage (CD) threshold, micro-cracks start to interact and coalesce, mostly through shearing. Therefore, the BPM with circular disks has limited application for simulation of crack interaction (Diederichs 2007).

The simplicity of generating tetrahedra grains in DEM for simulation of fracturing in rock is leading to increasing use of this approach. The micro-properties of the tetrahedra models can be calibrated to simulate the exact macro-properties of rock tested in the laboratory, however at the micro-scale, in contrast to the BPM models, most of the failure occurs in shear (Gao \& Stead 2014). In Figure 1(a), the potential sliding path in a tetrahedra model is shown (red lines). While the tetrahedra model includes smooth pathways that encourage shear sliding, the grain boundaries of the Voronoi model (Figure 1(b)) creates asperities and rough failure paths, which lead to extensile opening of some grain boundaries and simultaneous shear sliding along other grain edges. This figure shows that the existence of these smooth pathways for cracking can encourage shear sliding.
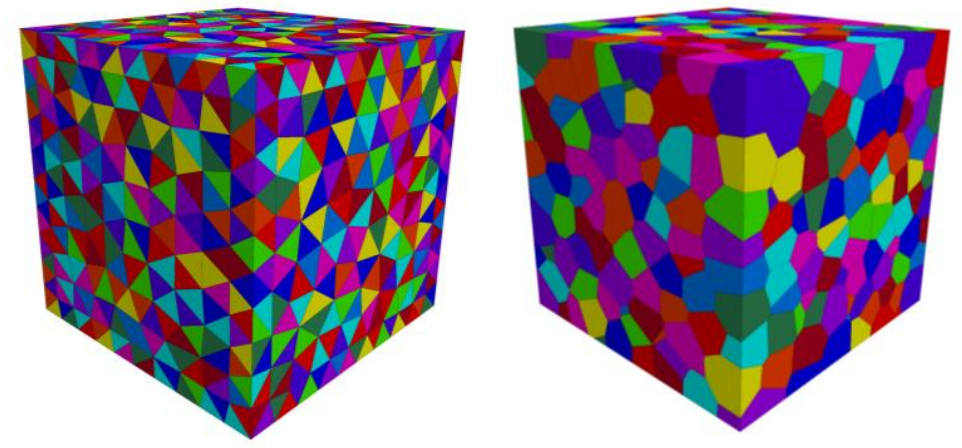

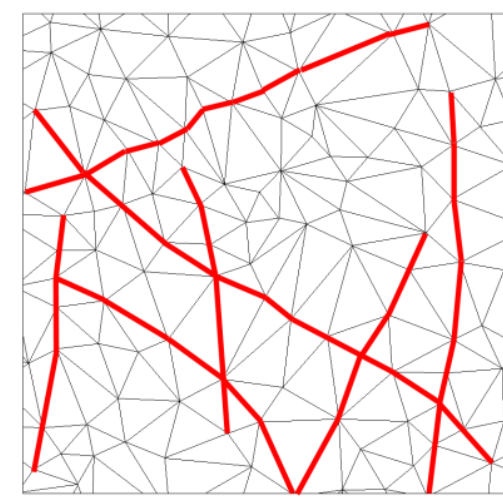

a

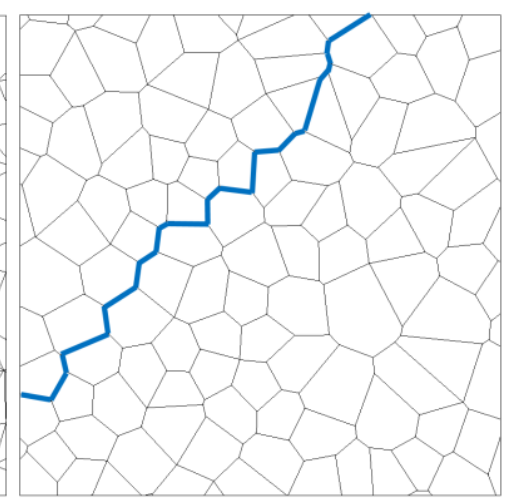

b

Figure 1 Smooth versus rough sliding paths for shearing in the: (a) tetrahedra; and, (b) Voronoi models. The conceptual example for sliding paths are shown as red and blue lines

\subsection{Laminated GBM for fabric-guided fracturing simulation}

Previous attempts to explicitly simulate mechanical anisotropic behaviour for brittle intact rocks by different researchers have mainly concentrated on introducing anisotropic damage to the intact rock or providing a non-random fracturing path within the rock mass. Diederichs et al. (2004) studied the effect of pre-existing damage in brittle rocks on their mechanical behaviour, such as $\mathrm{Cl}$ and $\mathrm{CD}$, by inducing different crack intensities (removing or breaking bonds between disks) at different orientations in their PFC2D models. In a hybrid continuum/discontinuum approach Mahabadi et al. (2012b) and Lisjak et al. (2014a) successfully applied a small-scale discrete fracture network (DFN) to a FDEM model to study the anisotropic behaviour of Opalinus Clay. They later extended this approach to a larger-scale to study the development of the excavation damage zone around tunnels excavated in this formation (Lisjak et al. 2014b). 
The Voronoi tessellation provides an opportunity to generate GBMs that resemble the fabric elements similar to those observed in reality. In the simplest form, a GBM with different scaling factors can be generated from a regular Voronoi tessellation to mimic the intensity of the anisotropy in the intact rock. Laminated GBMs with fabrics composed of elongated 3D Voronoi grains can be constructed with scaling. Examples of generated cylindrical specimens with five different fabric orientations with respect to the loading direction are illustrated in Figure 2. For generation of these specimens, a prismatic domain with height/width ratio equal to the desired length/width ratio of grains is generated, scaled and then rotated for proper fabric orientation. The generated model is then exported to 3DEC and cut for a cylindrical specimen.

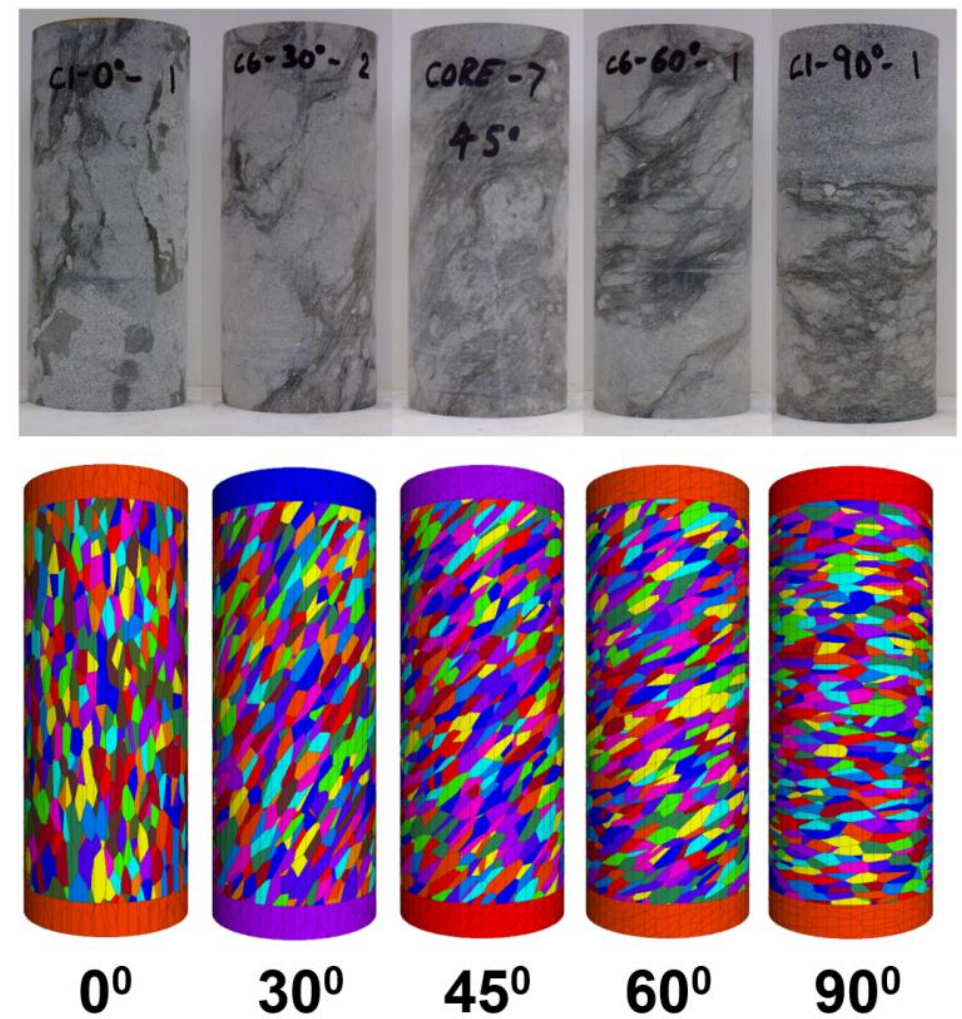

Figure 2 The limestone specimens with different fabric orientations with respect to the loading direction (before testing) and the corresponding 3DEC models

\section{Calibration of model parameters}

A set of laboratory data from unconfined compressive strength (UCS) tests on an argillaceous limestone was used for calibration of the model parameters. The calibration process was conducted by deciding on an initial value for the grains' $I / w$ ratio and adjusting the micro-parameters, according to the calibration procedure described by Ghazvinian et al. (2014) for the horizontally $\left(90^{\circ}\right)$ and vertically $\left(0^{\circ}\right)$ laminated models simultaneously with an identical set of micro-parameters to achieve the proper elastic constants. Then, the strength-related micro-parameters were adjusted for the horizontal model to calibrate its strength properties. Subsequently, by applying those micro-parameters to the vertically laminated model and fine-tuning the grains' $I / W$ ratio to attain the proper strength macro-properties, the global set of micro-parameters for the entire suite of specimens with different fabric orientations was obtained. It should be noted that elastic grains are used for these models and the strength degradation is a result of slip or tensile failure at the contact between the grains. The stress-strain curves for the numerical and laboratory specimens with vertical and horizontal fabrics are shown in Figure 3. The sudden post-peak stress drops, as observed for the $90^{\circ}$ laboratory specimen in Figure 3, may not be fully captured in these models since fracturing through the grains (blocks) are inhibited for computational efficiency. The calibrated micro-properties, listed in Table 1, were applied to the suite of GBMs with five different fabric orientations, as shown in Figure 2. 
Table 1 Calibrated model parameters based on the horizontal and vertical laminated models

\begin{tabular}{ll}
\hline Contact micro-parameters & \\
\hline Contact normal stiffness $\left(k_{n}\right)$ & $46,000 \mathrm{GPa} / \mathrm{m}$ \\
\hline Contact normal to shear stiffness ratio $\left(k_{n} / k_{s}\right)$ & 8 \\
\hline Contact peak cohesion $\left(c_{\mathrm{p}}\right)$ & $50 \mathrm{MPa}$ \\
\hline Contact residual cohesion $\left(c_{\mathrm{r}}\right)$ & $0 \mathrm{MPa}$ \\
\hline Contact peak tensile strength $\left(T_{\mathrm{p}}\right)$ & $5 \mathrm{MPa}$ \\
\hline Contact residual tensile strength $\left(T_{\mathrm{r}}\right)$ & $0 \mathrm{MPa}$ \\
\hline Contact peak friction $\left(\phi_{\mathrm{p}}\right)($ pre-crack formation) & $0^{\circ}$ \\
\hline Contact residual friction $\left(\phi_{\mathrm{r}}\right)$ & $25^{\circ}$ \\
\hline Grain (block) Young's modulus $(E)$ & $50 \mathrm{GPa}$ \\
\hline Grain (block) Poisson's ratio $(v)$ & 0.10 \\
\hline Grain (block) length to width ratio $(I / w)$ & 2 \\
\hline
\end{tabular}

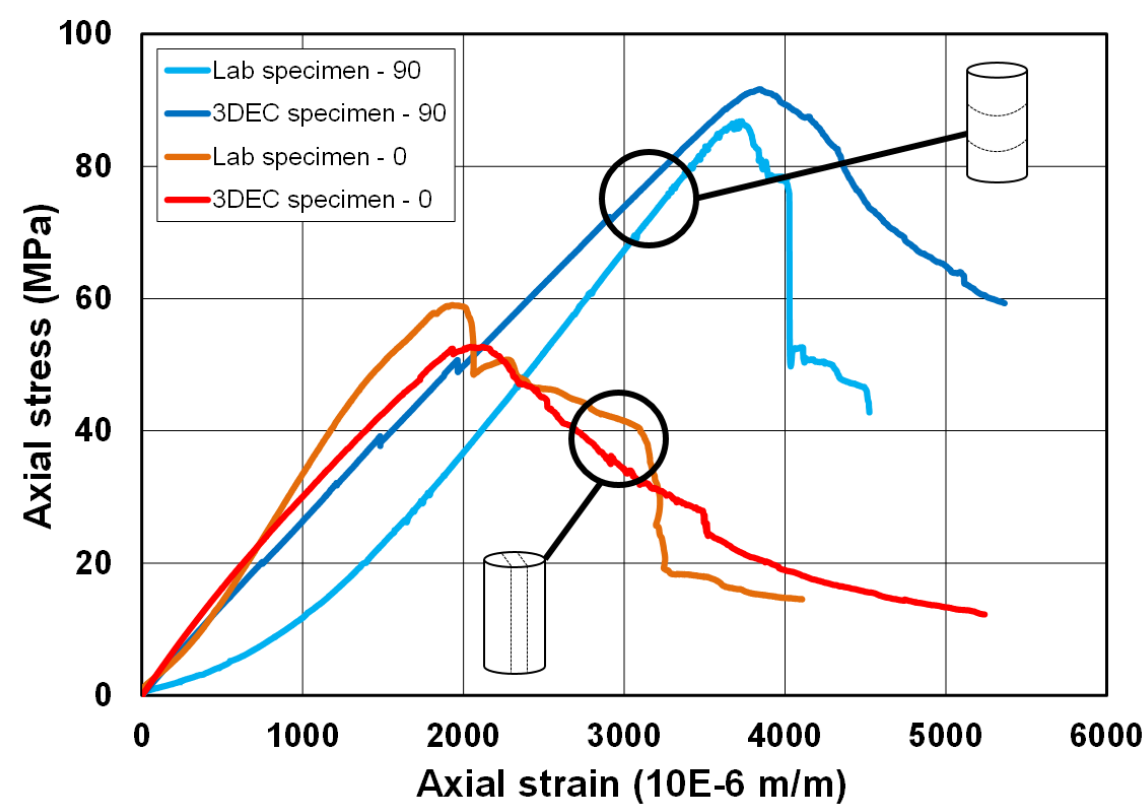

Figure 3 Stress-strain curves for $0^{\circ}$ and $90^{\circ}$ specimens tested in the laboratory and numerically simulated in 3DEC

As shown in Figure 4, the laminated GBM approach was successful in capturing the effect of fabric orientation on the failure mode of the models. In this figure, which shows the fractures in the models after failure on a plane cut through the centre of the model, the switch between the failure modes can be observed to occur as a function of the fabric orientation. Axial splitting and brittle failure can be seen in the $0^{\circ}$ and $90^{\circ}$ specimens respectively, and the formation of shear bands is evident in the other orientations. Remarkably, the formation of axial micro-fractures and their influence on the formation of a shear band by kinking can be seen in the $45^{\circ}$ model. 


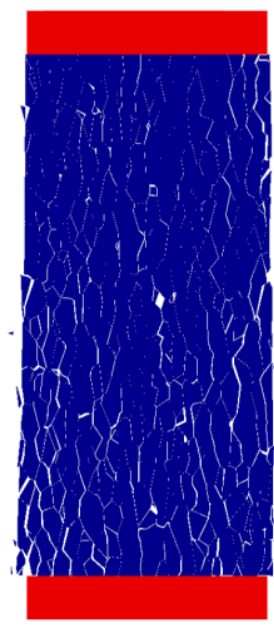

$0^{0}$

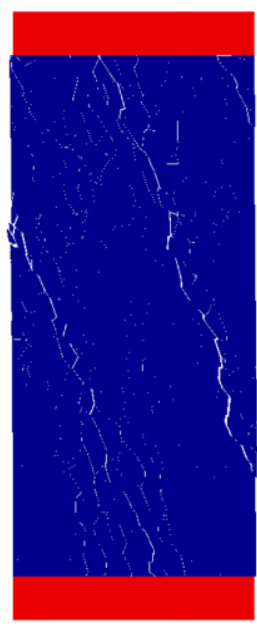

$30^{0}$

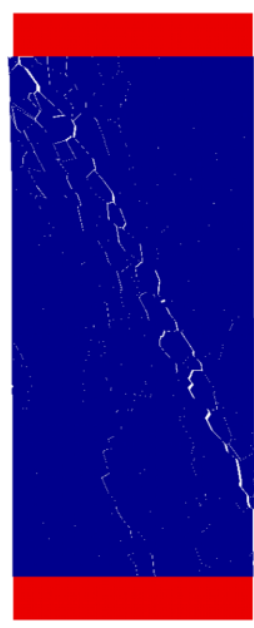

$45^{0}$

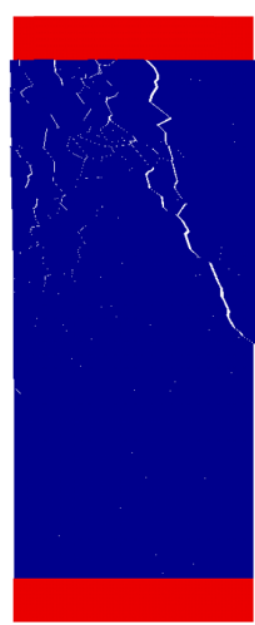

$60^{\circ}$

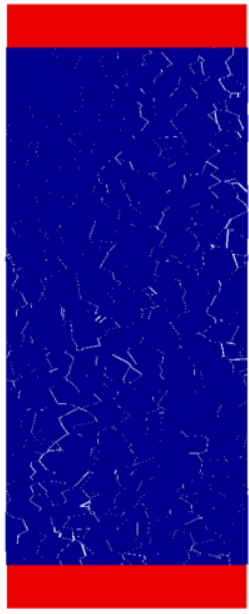

$90^{0}$

Figure 4 Cross-sections through the laminated GBMs after the failure

The comparison between the laboratory testing results of the limestone and the corresponding numerical macro-properties are shown in Figure 5. The UCS and Cl thresholds between the two sets of data are in good agreement and the classical U-shaped behaviour (Jaeger \& Cook 1969) for anisotropic rocks is well-captured by the GBMs. The elastic response of the numerical models, which were calibrated before the strength properties, approximately captures the lower-bound Young's moduli (except the vertically and horizontally laminated models) and the upper-bound of the laboratory measured Poisson's ratios. Since calibration of the strength-related components of the macro-behaviour for GBMs takes place after the calibration of the elastic response, the Young's moduli and the Poisson's ratio of the models can be slightly altered, as observed in Figure 5. Therefore, following the calibration procedure for a couple of iterations between adjustments for the elastic response and strength of the models can increase the accuracy of the calibrated micro-parameters.
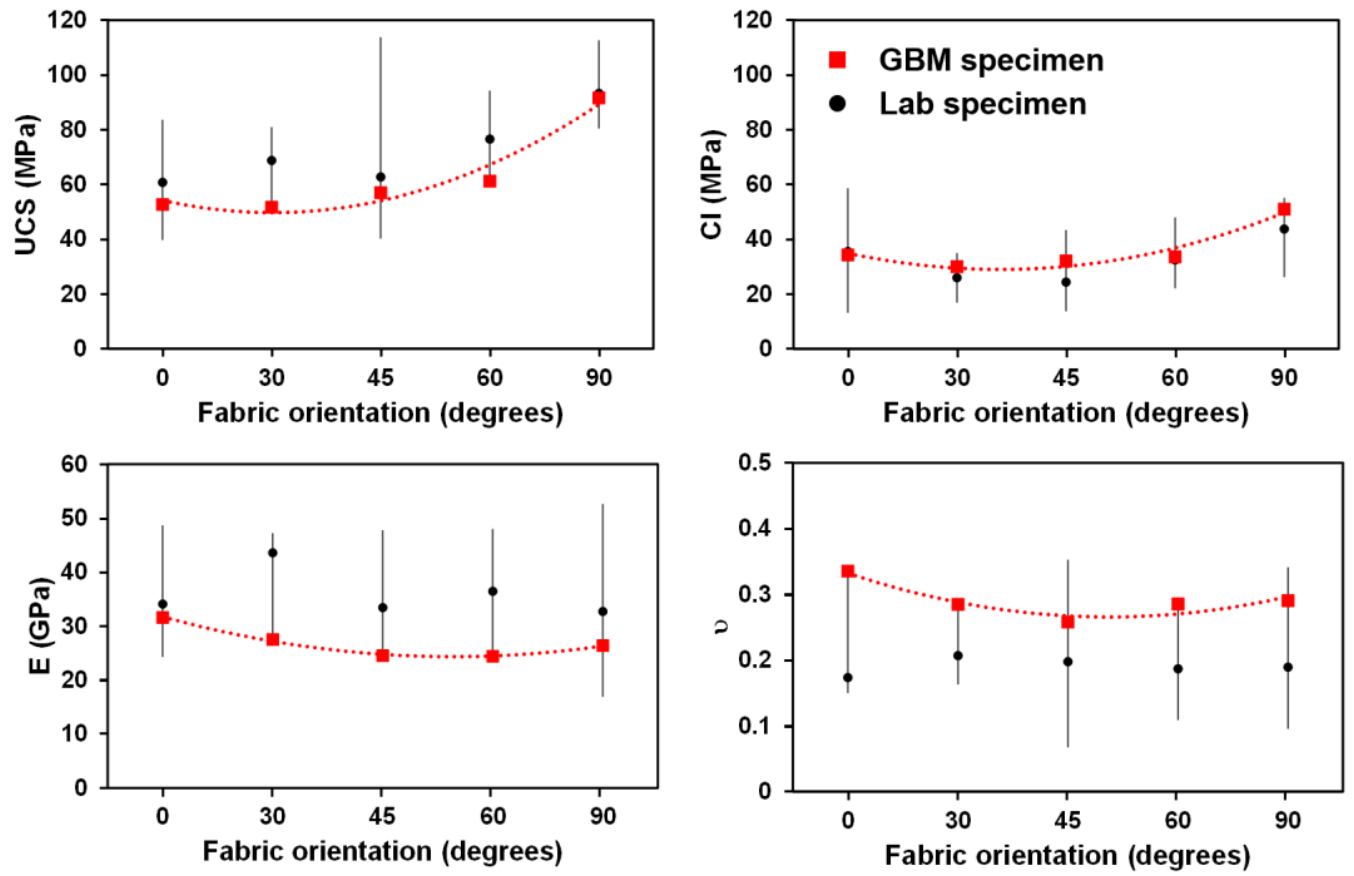

Figure 5 Comparison between the mechanical properties of the limestone measured in the laboratory and simulated in 3DEC (the dotted lines are 2 nd order polynomial best fit to the 3DEC results) 


\section{Simulation of rock mass response to excavation}

To demonstrate the ability of the Voronoi tessellated models in 3DEC for capturing the failure processes around deep underground openings, a square tunnel with arched ceiling was simulated in a laminated ground. The tunnel is $5 \mathrm{~m}$ wide and $5.5 \mathrm{~m}$ high at the highest point and simulated for a $4 \mathrm{~m}$ length section. The tunnel is surrounded with a Voronoi region, $16 \mathrm{~m}$ wide, that allows for propagation of fractures. There is an elastic buffer zone around the Voronoi region that allows for smooth distribution of reaction forces from the model boundaries towards the Voronoi region. The vertical stress in the model corresponds to 2,500 $\mathrm{m}$ overburden (approximately $66 \mathrm{MPa}$ ). The major principal stress is perpendicular in the horizontal plane to the tunnel axis with $\mathrm{k}_{\mathrm{H}}=2$ and the intermediate stress is aligned with the tunnel axis with $\mathrm{k}_{\mathrm{h}}=1.5$. The model schematic is shown in Figure 6.

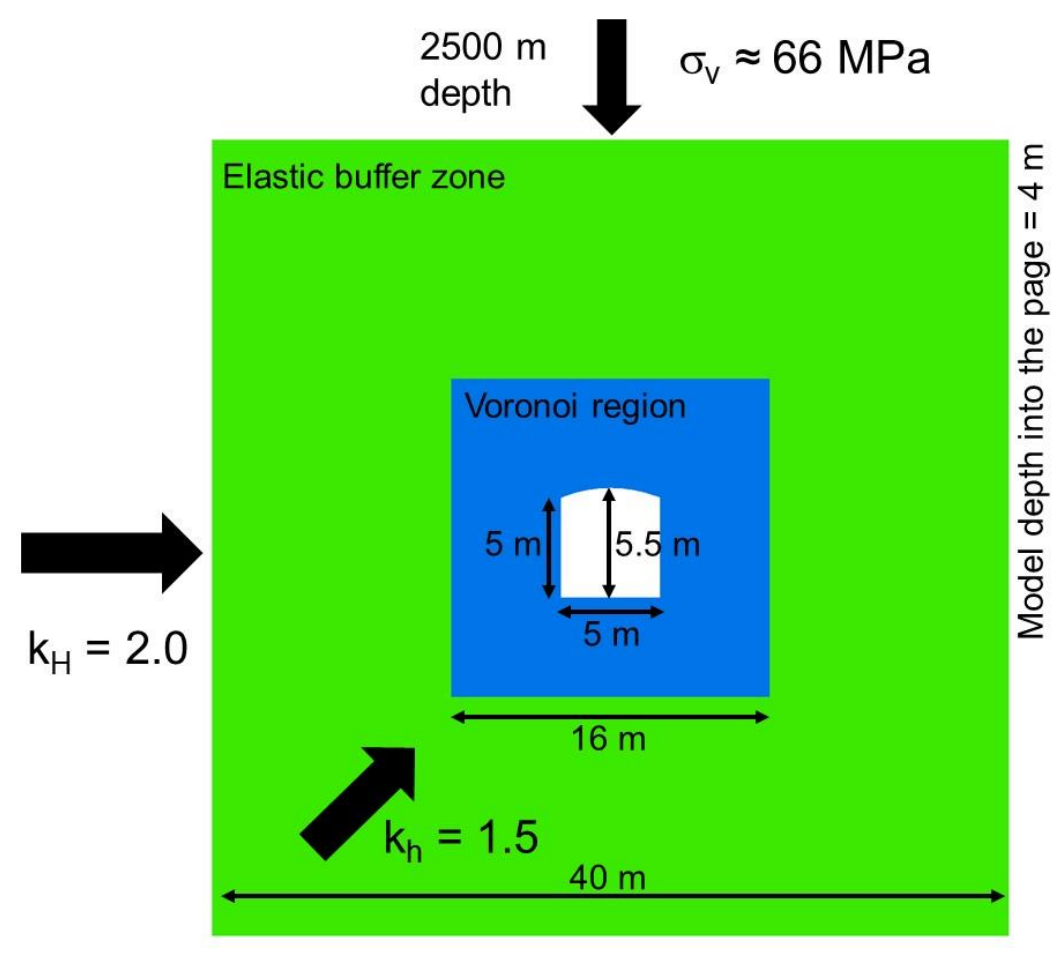

Figure 6 Model geometry and applied stress condition

A suite of Voronoi geometries with five different fabric orientations $\left(0^{\circ}, 30^{\circ}, 45^{\circ}, 60^{\circ}\right.$ and $\left.90^{\circ}\right)$ with respect to the direction of the major principal stress were generated in Neper version 3 (Quey et al. 2011) and imported into 3DEC (Figure 7). The Voronoi regions measure $16 \times 16 \times 4 \mathrm{~m}$ in size and are tessellated with 15,000 Voronoi blocks.

The calibrated model properties in Section 3 were applied to the Voronoi region. To account for stiffening of the Voronoi region, due to upscaling, the Voronoi contact normal stiffness $\left(k_{n}\right)$ was reduced to $25,000 \mathrm{GPa} / \mathrm{m}$ while the contact normal to shear stiffness ratio $\left(k_{n} / k_{s}\right)$ was kept constant equal to eight. The new value for the Voronoi contact normal stiffness was estimated by decreasing the original value of $k_{n}$ $(46,000 \mathrm{GPa} / \mathrm{m})$ in increments and running the model until a seamless transition of stresses were achieved at the boundary between the Voronoi region and elastic buffer zone. The Young's modulus of $28 \mathrm{GPa}$ and Poisson's ratio of 0.28 was used for the elastic buffer zone to represent average elastic properties of the limestone with different fabric orientation.

The tunnel excavation in the model was performed by removal of the tunnel material and gradual relaxation of the reaction forces on the excavation boundary until the boundary forces are completely removed. 


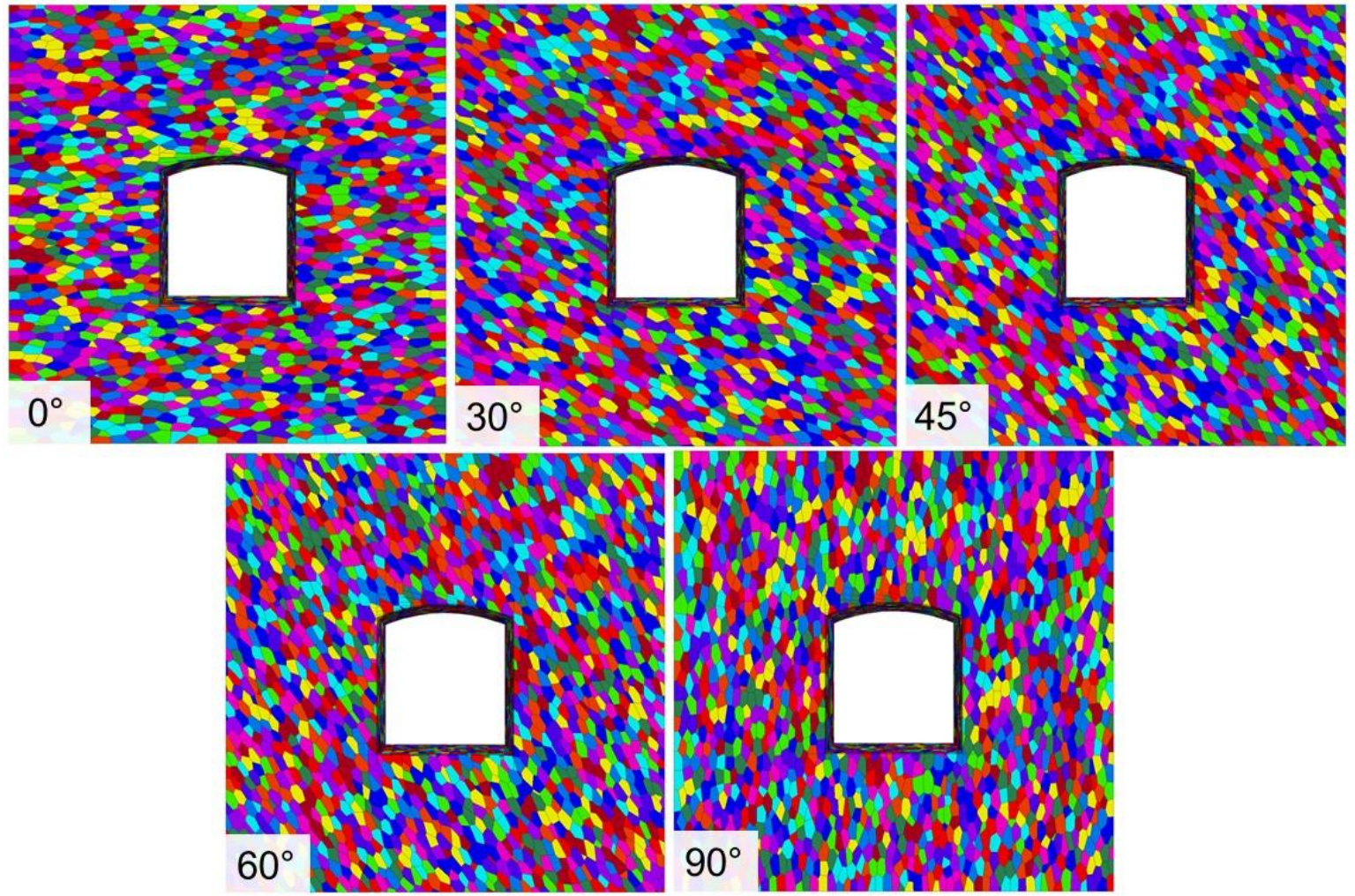

Figure 7 Excavated tunnel within the Voronoi region with different fabric orientations

The cross-sectional view of the major and minor principal stresses after mining the tunnel are shown in Figure 8. The associated displacement magnitudes of the rock mass in the vicinity of the tunnel are shown in Figure 9. In this figure the completely detached rock fragments are presented as well. The maximum displacement of the rock mass is observed to occur in the side walls. The large magnitude displacements that are observed at the floor and the back of the $0^{\circ}, 30^{\circ}, 45^{\circ}$ and $60^{\circ}$ models are associated with detachment of blocks. The investigation of detached Voronoi fragments in Figure 9 shows that the floor heave is controlled by buckling of the strata, while the geometrical restriction imposed by the arch in the roof controls this buckling to some extent. The maximum fracturing of the floor and back occur for the $30^{\circ}$ and $45^{\circ}$ models in a shear dominated mode. While the shear failure of the back and the floor is more moderate for the $60^{\circ}$ model, in comparison to the $30^{\circ}$ and $45^{\circ}$ models, the shear fractures start to progress towards the side walls. This can also be verified in the major principal stress graph (Figure 8) where the low tangential stress in the sidewalls penetrate deeper into the rock mass compared to other orientations. Finally, for the $90^{\circ}$ model, not much failure is observed other than some random block detachment in the sidewalls. This result, which agrees with Figure 5, is intuitive as the strongest fabric orientation is normal to the principal load.

The normal (blue) and shear (red) displacements larger than $5 \mathrm{~mm}$ at the Voronoi contacts are shown in Figure 10. No formal significance should be placed in the $5 \mathrm{~mm}$ displacement, which is merely chosen as a constant value for comparison only between different models. It is interesting to notice that similar contacts are dilated in shear and normal directions in the $0^{\circ}$ model. However, in the $30^{\circ}, 45^{\circ}$ and $60^{\circ}$ models the contacts displaced in shear are aligned parallel or sub-parallel to the fabric orientation, whereas the contacts dilated in tension have random orientations. This can be attributed to the fact that fracturing in $0^{\circ}$ model is occurring in extensile mode (buckling), whereas in the $30^{\circ}, 45^{\circ}$ and $60^{\circ}$ models shearing is the dominant mode of displacement and normal opening of some contacts are occurring due to the formed asperities (to allow for further shear displacement). This is in line with what was discussed in Section 2.1. 


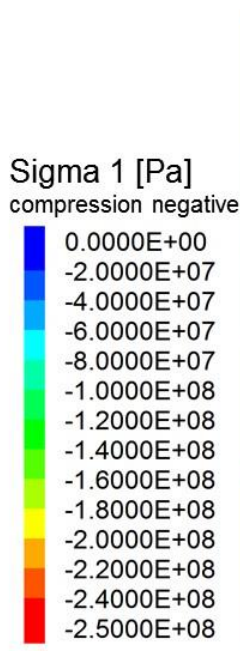

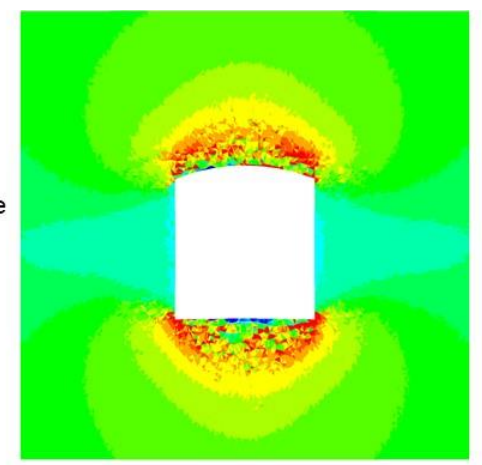

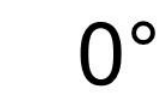

Sigma $3[\mathrm{~Pa}]$ compression negative

3.0000E+07

$1.5000 \mathrm{E}+07$

$0.0000 E+00$

$-1.5000 \mathrm{E}+07$

$-3.0000 \mathrm{E}+07$

$-4.5000 \mathrm{E}+07$

$-6.0000 \mathrm{E}+07$

$-7.5000 \mathrm{E}+07$

$-9.0000 \mathrm{E}+07$

$-1.0500 \mathrm{E}+08$

$-1.2000 E+08$

$-1.3500 \mathrm{E}+08$

$-1.4000 \mathrm{E}+08$
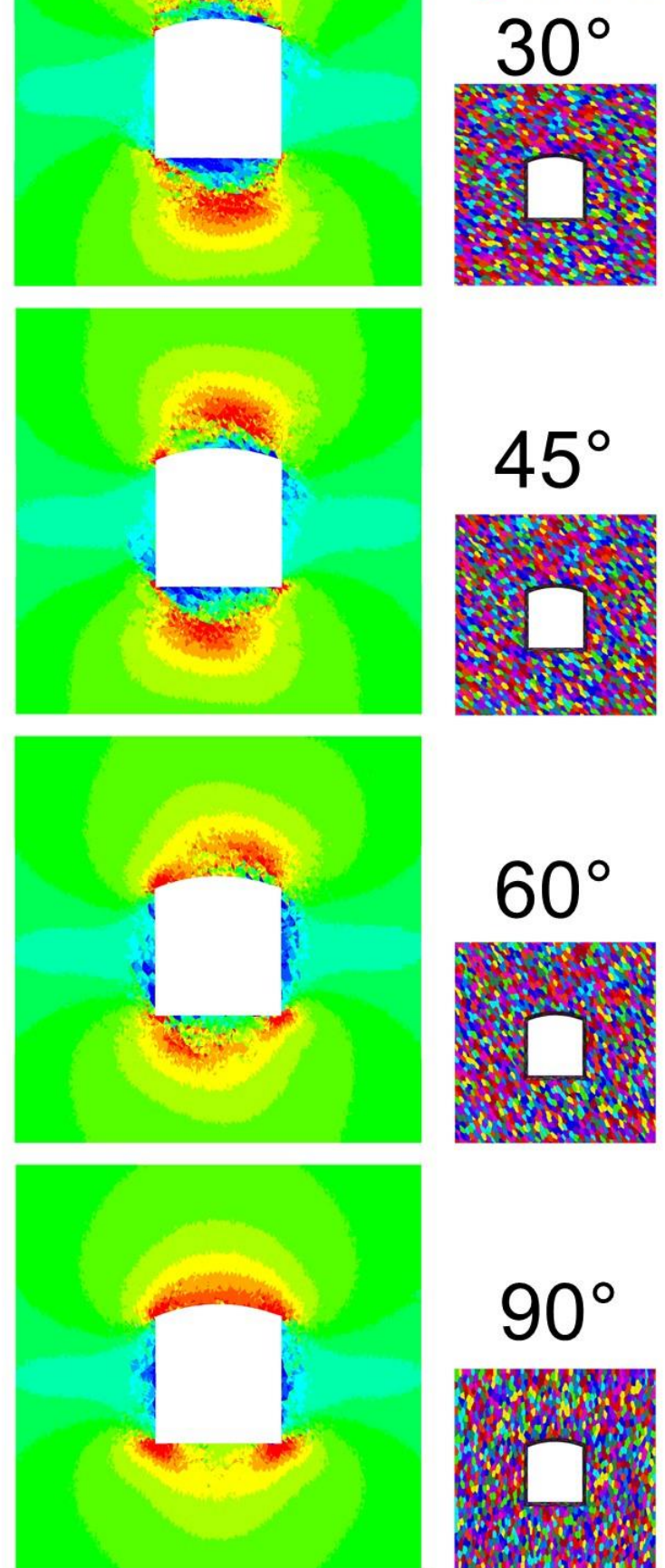
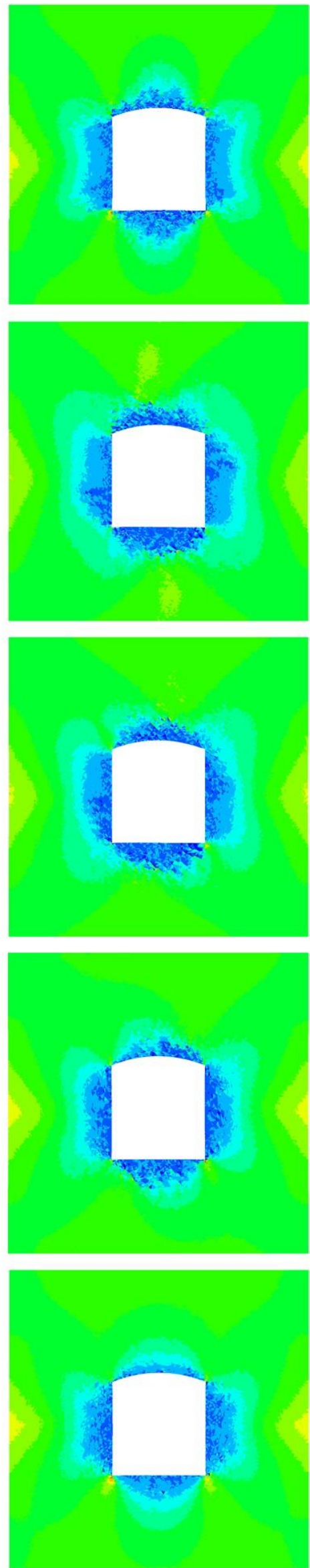

Figure 8 Major and minor principal stresses after complete excavation of the tunnel 


$$
\begin{array}{r}
\text { Displacement ma } \\
1.5000 \mathrm{E}-02 \\
1.4000 \mathrm{E}-02 \\
1.3000 \mathrm{E}-02 \\
1.2000 \mathrm{E}-02 \\
1.1000 \mathrm{E}-02 \\
1.0000 \mathrm{E}-02 \\
9.0000 \mathrm{E}-03 \\
8.0000 \mathrm{E}-03 \\
7.0000 \mathrm{E}-03 \\
6.0000 \mathrm{E}-03 \\
5.0000 \mathrm{E}-03 \\
4.0000 \mathrm{E}-03 \\
3.0000 \mathrm{E}-03 \\
2.0000 \mathrm{E}-03 \\
1.0000 \mathrm{E}-03 \\
0.0000 \mathrm{E}+00
\end{array}
$$
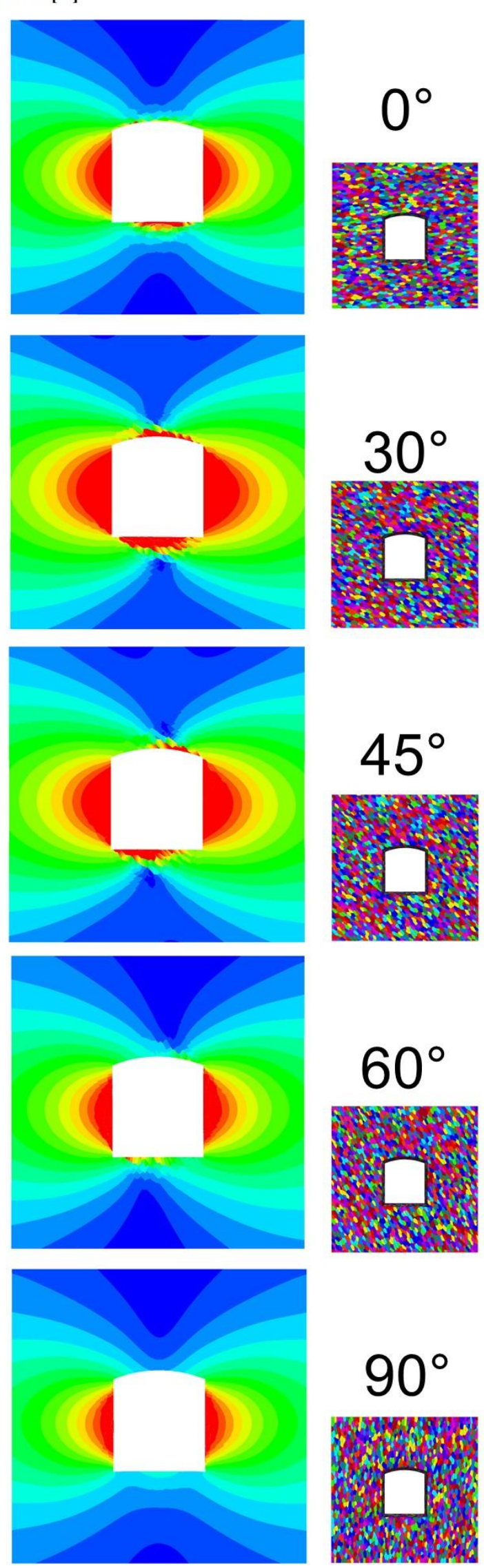
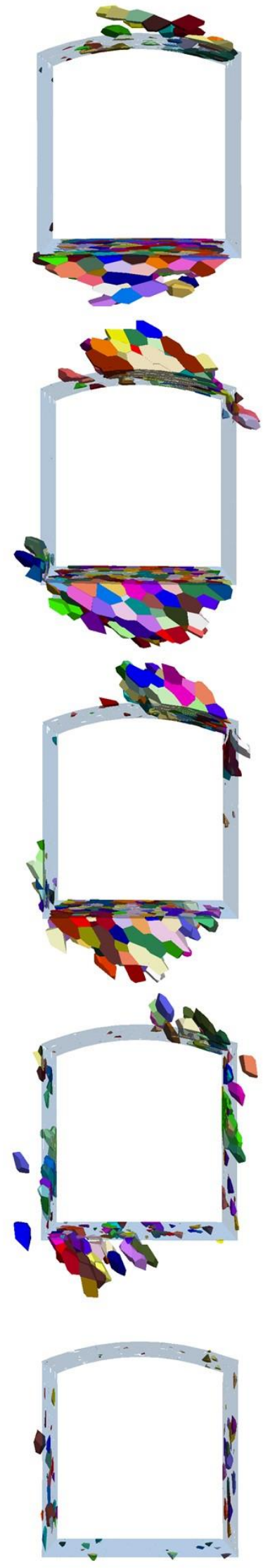

Figure 9 Displacement magnitude (left); and completely detached Voronoi fragments (right), after complete excavation of the tunnel 

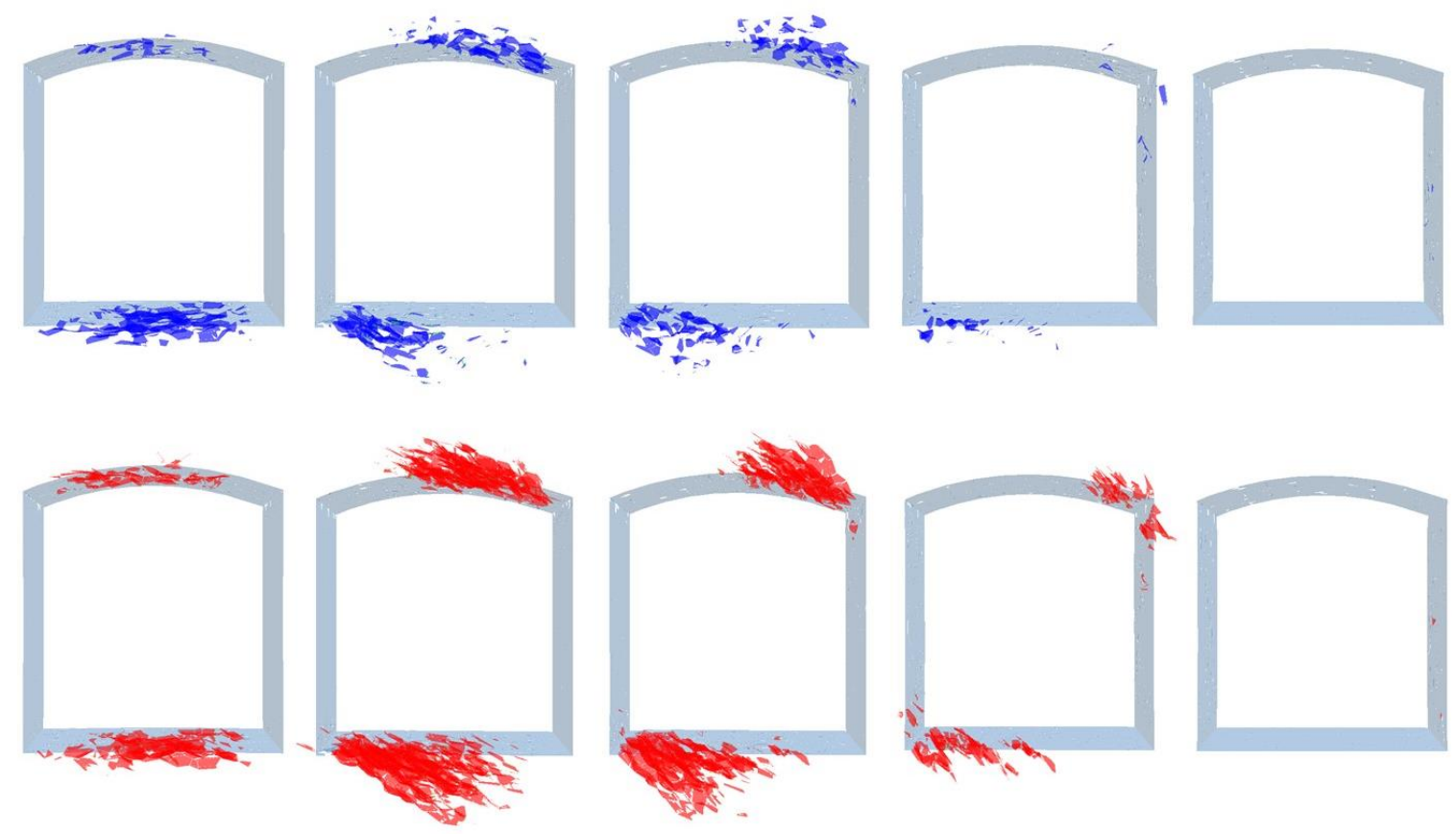

$$
0^{\circ}
$$

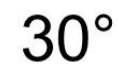

$45^{\circ}$

$60^{\circ}$

$90^{\circ}$

Figure 10 Voronoi contacts with: (top) normal; and, (bottom) shear, displacements larger than $5 \mathrm{~mm}$ after complete excavation of the tunnel

\section{Conclusion}

The recently developed 3D Voronoi GBMs were calibrated and used for simulation of micro-fracturing in laboratory scale limestone specimens, which included a fabric. Furthermore, the model was used to demonstrate rock damage and fracturing around the periphery of a deep underground opening in a similar rock type by means of proper up-scaling rules. The up-scaled model was solely developed for investigation of laminated GBM's ability in capturing fabric-guided fracturing within highly anisotropic rock masses and was not intended to replicate any site specific conditions. The modelling results are demonstrating the ability of this technique in capturing the correct mechanisms of failure whether spalling, buckling or shearing, depending on the relative orientation of the fabric and in situ stress tensor around an excavation, as well as the in situ stress magnitude for the mobilised zone (depth of yield) surrounding the excavation. While the laboratory numerical specimens were calibrated for crack initiation and crack propagation thresholds, those thresholds were not investigated in the up-scaled models in this study, it is possible to capture the depth of yielded zone as well as the seismogenic zone in to the rock mass.

3D Voronoi tessellated models can be used as the building block for the synthetic rock mass (SRM) to represent intact rock. Its combination with the in situ joint network, commonly referred to as the DFN, can represent rock masses that can be numerically investigated. The regular and laminated GBMs can be used for SRM representation of rock masses, including intact rock with isotropic or inherent anisotropic mechanical behaviour.

\section{References}

Cho, N, Martin, CD \& Sego, DC 2007, 'A clumped particle model for rock', International Journal of Rock Mechanics and Mining Sciences, vol. 44, no. 7, pp. 997-1010.

Cundall, PA 1988, 'Formulation of a three-dimensional distinct element model - Part I. A scheme to detect and represent contacts in a system composed of many polyhedral blocks', International Journal of Rock Mechanics and Mining Sciences and Geomechanics Abstracts, vol. 25, no. 3, pp. 107-116.

Cundall, PA \& Hart, RD 1985, Development of generalized 2-D and 3-D distinct element programs for modeling jointed rock, Itasca Consulting Group Inc., Minneapolis. 
Damjanac, B, Board, M, Lin, M, Kicker, D \& Leem, J 2007, 'Mechanical degradation of emplacement drifts at Yucca Mountain A modeling case study: Part II: Lithophysal rock', International Journal of Rock Mechanics and Mining Sciences, vol. 44, no. 3, pp. 368-399.

Diederichs, MS 2003, 'Rock fracture and collapse under low confinement conditions', Rock Mechanics and Rock Engineering, vol. 36, no. 5, pp. 339-381.

Diederichs, MS 2007, 'The 2003 Canadian geotechnical colloquium: Mechanistic interpretation and practical application of damage and spalling prediction criteria for deep tunnelling', Canadian Geotechnical Journal, vol. 44, no. 9, pp. 1082-1116.

Diederichs, MS, Kaiser, PK \& Eberhardt, E 2004, 'Damage initiation and propagation in hard rock during tunnelling and the influence of near-face stress rotation', International Journal of Rock Mechanics and Mining Sciences, vol. 41, no. 5, pp. 785-812.

Gao, FQ \& Stead, D 2014, The application of a modified Voronoi logic to brittle fracture modelling at the laboratory and field scale', International Journal of Rock Mechanics and Mining Sciences, vol. 68, pp. 1-14.

Garza-Cruz, TV, Pierce, M \& Kaiser, PK 2014 'Use of 3DEC to study spalling and deformation associated with tunnelling at depth', in M Hudyma \& Y Potvin (eds), Proceedings of the Seventh International Seminar on Deep and High Stress Mining, Australian Centre for Geomechanics, Perth, pp. 421-434.

Ghazvinian, E 2010, 'Modelling and testing strategies for brittle fracture simulation in crystalline rock samples', MSc thesis, Queen's University, Kingston.

Ghazvinian, E, Diederichs, MS \& Quey, R 2014, '3D random Voronoi grain-based models for simulation of brittle rock damage and fabric-guided micro-fracturing', Journal of Rock Mechanics and Geotechnical Engineering, vol. 6, no. 6, pp. 506-521.

Itasca 2008a, PFC2D (Particle Flow Code 2D), software, version 4.0, Itasca Consulting Group Inc., Minneapolis.

Itasca 2008b, PFC3D (Particle Flow Code 3D), software, version 4.0, Itasca Consulting Group Inc., Minneapolis.

Itasca 2012, FLAC (Fast Lagrangian Analysis of Continua), software, version 7.0, Itasca Consulting Group Inc., Minneapolis.

Itasca 2013, 3DEC (3 Dimensional Distinct Element Code), software, version 5.0, Itasca Consulting Group Inc., Minneapolis.

Jaeger, JC \& Cook, NG 1969, Fundamentals of Rock Mechanics, Methuen \& Co Ltd, London.

Karampinos, E, Hadjigeorgiou, J, Hazzard, J \& Turcotte, P 2015, 'Discrete element modelling of the buckling phenomenon in deep hard rock mines', International Journal of Rock Mechanics and Mining Sciences, vol. 80, pp. 346-356.

Kazerani, T 2013, 'A discontinuum-based model to simulate compressive and tensile failure in sedimentary rock', Journal of Rock Mechanics and Geotechnical Engineering, vol. 5, no. 5, pp. 378-388.

Kazerani, T \& Zhao, J 2010, 'Micromechanical parameters in bonded particle method for modeling of brittle material failure', International Journal for Numerical and Analytical Methods in Geomechanics, vol. 34, no. 18, pp. 1877-1895.

Lan, H, Martin, CD \& Hu, B 2010, 'Effect of heterogeneity of brittle rock on micromechanical extensile behavior during compression loading', Journal of Geophysical Research, vol. 115, pp. 1-14.

Lisjak, A, Grasselli, G \& Vietor T 2014b, 'Continuum-discontinuum analysis of failure mechanisms around unsupported circular excavations in anisotropic clay shales', International Journal of Rock Mechanics and Mining Sciences, vol. 65, pp. 96-115.

Lisjak, A, Tatone, BS, Grasselli, G \& Vietor, T 2014a, 'Numerical modelling of the anisotropic mechanical behaviour of Opalinus Clay at the laboratory-scale using FEM/DEM', Rock Mechanics and Rock Engineering, vol. 47, no. 1, pp. 187-206.

Mahabadi, OK, Lisjak, A, Grasselli, G \& Munjiza, A 2012a, 'Y-Geo: a new combined finite-discrete element numerical code for geomechanical applications', International Journal of Geomechanics, vol. 12, no. 6, pp. 676-688.

Mahabadi, OK, Randall, NX, Zong, Z \& Grasselli, G 2012b, 'A novel approach for micro-scale characterization and modeling of geomaterials incorporating actual material heterogeneity', Geophysical Research Letters, vol. 39.

Potyondy, DO 2012, 'A flat-jointed bonded-particle material for hard rock', in Proceedings of the 46th U.S. Rock Mechanics/Geomechanics Symposium, American Rock Mechanics Association, Chicago, USA.

Potyondy, DO \& Cundall, PA 2004, 'A bonded-particle model for rock', International Journal of Rock Mechanics and Mining Sciences, vol. 41 , no. 8 , pp. 1329-1364.

Quey, R, Dawson, PR \& Barbe, F 2011, 'Large-scale 3D random polycrystals for the finite element method: generation, meshing and remeshing', Computer Methods in Applied Mechanics and Engineering, vol. 200, no. 17, pp. 1729-1745.

Scholtès, L \& Donzé, FV 2013, 'A DEM model for soft and hard rocks: role of grain interlocking on strength', Journal of the Mechanics and Physics of Solids, vol. 61, no. 2, pp. 352-369.

Sharrock, GB \& Cuello, DA, 2016, 'Geotechnical milestones at Mount Lyell Mine', Proceedings of the Seventh International Conference and Exhibition on Mass Mining (MassMin 2016), pp. 427-438.

Sweby, G, Dight, P \& Potvin, Y 2016, 'A numerical modelling case study - correlation of ground support instrumentation data with a three dimensional inelastic model', in E Nordlund, TH Jones \& A Eitzenberger (eds), Proceedings of the Eighth International Symposium on Ground Support in Mining and Underground Construction, 12-14 September 2016, Luleå University of Technology, Luleå.

Turichshev, A \& Hadjigeorgiou, J 2016, 'Simulating intact rock behaviour using bonded particle and bonded block models', Proceedings of the Seventh International Conference and Exhibition on Mass Mining (MassMin 2016), pp. 453-460.

Vakili, A, Albrecht, J \& Sandy, M 2014, 'Rock strength anisotropy and its importance in underground geotechnical design', Proceedings of AusRock 2014: Third Australasian Ground Control in Mining Conference, pp. 167-180.

Yoon, JS, Jeon, S, Stephansson, O, Zang, A \& Dresen, G 2008, 'A new method of microparameter determination for PFC2D synthetic rock model generation', Proceedings of the 1st International FLAC/DEM Symposium on Numerical Modeling, Itasca Consulting Group Inc., Minneapolis.

You, S, Zhao, GF \& Ji, HG 2011, 'Model for transversely isotropic materials based on distinct lattice spring model (DLSM)', Journal of Computers, vol. 6, no. 6, pp. 1139-1144. 